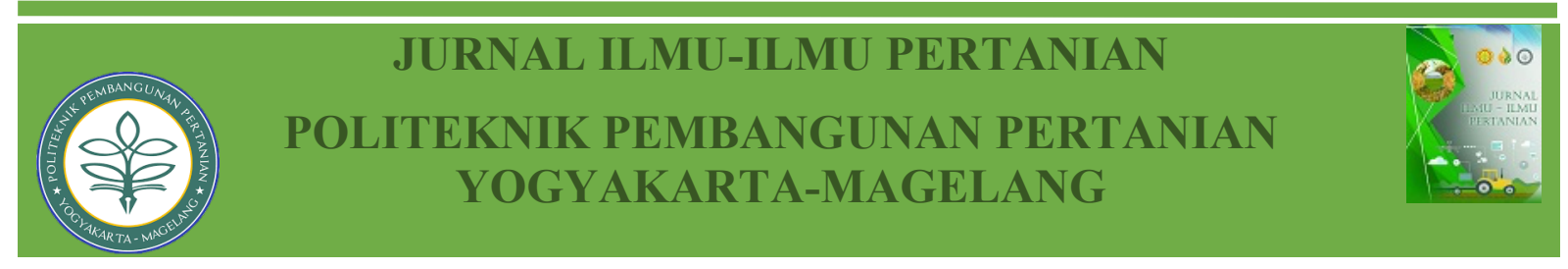

\title{
PENGEMBANGAN USAHA JAHE MERAH (Zingiber offcinale var rubrum) SEBAGAI MODEL PEMBERDAYAAN MASYARAKAT (STUDI KASUS DI VISTA AGRO MEDIA D.I. YOGYAKARTA)
}

\author{
William Nichodemust Richard ${ }^{1}$, Gunawan Yulianto ${ }^{2 *}$, Rajiman ${ }^{3}$ \\ ${ }^{1}$ Politeknik Pembangunan Pertanian Yogyakarta Magelang, Kota Yogyakarta, 55167 \\ ${ }^{2}$ Politeknik Pembangunan Pertanian Yogyakarta Magelang, Kota Yogyakarta, 55167 \\ ${ }^{3}$ Politeknik Pembangunan Pertanian Yogyakarta Magelang, Kota Yogyakarta, 55167
}

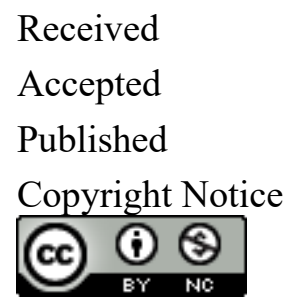

: December $7^{\text {th }}, 2021$

: January $16^{\text {th }}, 2021$

: January $16^{\text {th }}, 2022$

: Authors retain copyright and grant the journal right of first publication with This work is licensed under a Creative Commons Attribution-Non Commercial 4.0 International License.

ABSTRAK: Kajian ini bertujuan untuk mengetahui penerapan teknologi inovasi, potensi peluang pasar dan model pemberdayaan masyarakat yang tepat dalam pengembangan usaha budidaya tanaman jahe merah di Vista Agro Media. Kajian dilaksanakan pada bulan Januari 2021 sampai dengan Juli 2021 di Tlogoadi, Mlati, Kabupaten Sleman. Metode penelitian yang digunakan yaitu deskriptif. Pemilihan lokasi dan teknik pengambilan informan dalam kajian dilakukan secara purposive. Teknik pengumpulan data menggunakan triangulasi dan FGD (Focus Group Discuccion). Analisis data dilakukan dengan cara tabulasi data berdasarkan hasil benchmarking yaitu membandingkan aspek teknologi inovasi budidaya dan aspek potensi peluang pasar pada usaha yang sejenis. Hasil analisis kajian menunjukkan bahwa (1) penerapan teknologi di Vista Agro Media yang sudah optimal dalam budidaya jahe merah ialah pemakaian plastik uv atau paranet serta pemberian pupuk organik berupa urine kelinci dan kompos. (2) Potensi dan peluang pasar pada Vista Agro media ialah lokasi yang strategis, produk yang ditawarkan selalu tersedia, harga yang murah. (3) Model Pemberdayaan yang dilaksanakan guna mendukung peningkatan produksi jahe merah ialah menjalin kerja sama dengan masyarakat dan mengajak mereka membudidayakan jahe merah sehingga saat panen hasil dapat dijual pada Vista Agro Media dan kedua belah pihak dapat saling diuntungkan. Kegiatan penyuluhan yang dilakukan ialah cara pembibitan jahe merah pada media polybag kepada KWT Umbulasri secara bersama-sama. Hasil penyuluhan tersebut menunjukkan adanya peningkatan aspek pengetahuan sebesar 96\%, lalu aspek sikap sebesar 98,66\% dan aspek keterampilan diukur dengan pengamatan praktik secara langsung dan di dukung posttest yaitu 98,66\%.

Kata kunci: Aspek teknologi, benchmarking, potensi peluang pasar, tanaman jahe merah.

ABSTRACT: This study aims to determine the application of innovative technology, potential market opportunities and appropriate community empowerment models in the development of

\footnotetext{
*Email Penulis Korespondensi: gnwyulianto@gmail.com williamnichorichard@gmail.com¹, gnwyulianto@gmail.com², rajimanwin@gmail.com³
} 
ginger cultivation business at Vista Agro Media. The study was conducted from January 2021 to July 2021 in Tlogoadi, Mlati, Sleman Regency. The research method used is descriptive. The selection of locations and techniques for taking informants in the study was carried out purposively. Data collection techniques using triangulation and FGD (Focus Group Discussion). Data analysis was carried out by tabulating data based on the results of benchmarking, namely comparing aspects of cultivation innovation technology and aspects of potential market opportunities in similar businesses. The results of the analysis of the study show that (1) the application of innovation technology in Vista Agro Media that has been optimal in red ginger cultivation is the provision ofplastic uv or paranet and the provision of organic fertilizer in the form of rabbit urine and compost. (2) Potential and market opportunities at Vista Agro media are strategic locations, products offered are always available, low prices. (3) The empowerment model implemented to support the increase in red ginger production is to collaborate with the community and invite them to cultivate red ginger so that when harvested the results can be sold to Vista Agro Media and both parties can benefit from each other. The counseling activity carried out was how to seed red ginger in polybag media to KWT Umbulasri together. The results of the counseling showed that there was an increase in the knowledge aspect by 96\%, then the attitude aspect by $98.66 \%$ and the skill aspect measured by direct practical observation and supported by the post test, by $98.66 \%$.

Keywords: technological aspect, benchmarking, red ginger plant, potential market opportunities.

\section{PENDAHULUAN}

Tanaman Jahe merah (Zingiber officinale var rubrum) merupakan salah satu komoditas ekspor rempah-rempah Indonesia. Di samping itu, jahe juga menjadi bahan baku obat tradisional yang memberikan peranan cukup berarti dalam penyerapan tenaga kerja dan penerimaan devisa negara (Balitro Litbang 2013).

Mengacu kepada Keputusan Menteri Pertanian 511/KPTS/PD.310/9/2006 komoditas tanaman obat yang difasilitasi pengembangannya melalui Program Pengembangan Hortikultura salah satunya ialah tanaman jahe merah. Target pengembangan dari pemerintah adalah pemenuhan kebutuhan permintaan dalam negeri, mendukung adanya bahan baku pengobatan tradisional, mendukung penyediaan bahan baku industri herbal dan saintifikasi jamu, serta mendorong penyediaan produk ekspor segar maupun hasil olahan primer (simplisia, bubuk, bahan kering, dan lain-lain).

Kementerian Pertanian melalui Direktorat Jendral Hortikultura dalam kebijakannya ditahun 2020 menghimbau kepada insan pertanian bahwa Indonesia sangat berpotensi dalam pengembangan tanaman obat pada lahan pekarangan karena Indonesia memiliki luas lahan pekarangan secara nasional sekitar 10.3 juta ha atau $14 \%$ dari keseluruhan luas lahan pertanian. Pemerintah mengajak masyarakat untuk menjadikan komoditas hortikultura, khususnya dibidang biofarmaka sebagai salah satu solusi pemberdayaan masyarakat agar dapat meningkatkan pendapatan dan kesejahteraannya.

Kabupaten Sleman merupakan D.I Yogyakarta merupakan salah satu sentra produksi tanaman jahe terbesar ke dua setelah Kulon Progo dengan luas panen mencapai $1.613,020 \mathrm{~m}^{2}$ dan produksi sebesar $3.833,768 \mathrm{~kg}$. Berdasarkan data BPS Kabupaten Sleman (2020) tahun 2018 luas panen tanaman jahe di Kabupaten Sleman mencapai $573.693 \mathrm{~m}^{2}$ dan produksi sebesar 1.556,081 kg. Sedangkan pada tahun 2019 luas panen menurun menjadi $120.807 \mathrm{~m}^{2}$ dan produksi juga menurun menjadi $636.931 \mathrm{~kg}$.

Vista Agro Media yang berdiri sejak 
2013 bergerak dibidang produksi bibit dan budidaya tanaman jahe merah. Produktivitas panen jahe merah dalam 1 polybag belum mencapai hasil sesuai standar yang ada yaitu sebanyak $2 \mathrm{~kg}$ sedangkan menurut Kosasih dan Irwan (2019) produktivitas panen jahe merah dalam 1 polybag dapat mencapai $5 \mathrm{~kg}$. Artinya dalam segi teknik budidaya masih belum optimal dan perlu adanya inovasi untuk meningkatkan produktivitas, dengan penerapan teknologi/inovasi budidaya yang tepat dan benar mulai dari tahap penyemaian sampai pemanenan.

Vista Agro Media juga dapat memanfaatkan potensi dan peluang pasar yang dimiliki seperti aspek lokasi, produk, konsumen, promosi, harga, serta kemitraan sehingga usaha yang dijalankan menjadi lebih maju dan berkembang serta dapat terus memperluas peluang pasarnya tidak hanya di wilayah Yogyakarta saja namun dapat menjangkau lebih luas lagi. Kepemilikan lahan yang terbatas kurang lebih $2000 \mathrm{~m}^{2}$, sedangkan permintaan konsumen akan jahe merah cukup tinggi, dapat disiasati dengan mengajak masyarakat tani sekitarnya dalam pengembangannya sehingga usaha ini dapat menjadi contoh model pemberdayaan masyarakat yang tepat. Dengan adanya keterlibatan masyarakat tani pada usaha tersebut, diharapkan kehidupan masyarakat sekitar dapat menjadi lebih baik dan sejahtera.

Tujuan pada kajian ini adalah mengetahui penerapan teknologi inovasi budidaya jahe merah di Vista Agro Media, mengembangkan potensi dan peluang pasar dalam usaha budidaya jahe merah serta, merancang model pemberdayaan masyarakat yang tepat dalam usaha budidaya jahe merah melalui kerja sama antara Vista Agro Media dan masyarakat sekitar.

\section{METODE}

Kajian ini dilaksanakan dari bulan Januari 2021 sampai dengan Juli 2021, dengan berlokasi di Vista Agro Media desa Tlogoadi, Mlati, Sleman, DI Yogyakarta. Metode penelitian yang digunakan yaitu deskriptif. Pemilihan lokasi dan teknik pengambilan informan kunci, utama dan tambahan dalam kajian dilakukan secara purposive dengan total 21 orang. Teknik pengumpulan data primer menggunakan teknik triangulasi (Sugiyono 2015). Julia (2005) mengemukakan pengumpulan data menggunakan teknik triangulasi (metode dan data) menawarkan kesempatan untuk meningkatkan kesahihan internal. Data primer diperoleh melalui observasi, wawancara serta FGD (Focus Group Discussion). Sedangkan data sekunder yang diperoleh melalui data programa kecamatan Mlati, profil desa Tlogoadi, BPS Kabupaten Sleman, Statistik Hortikultura DIY. Analisis data yang dilakukan dalam kajian ini yaitu dengan cara tabulasi data berdasarkan hasil benchmarking dimana membandingkan aspek teknologi inovasi budidaya dan aspek potensi peluang pasar pada usaha yang sejenis, dari aspek teknologi yang paling unggul dan peluang pasar yang paling menguntungkan ini yang akan dipilih untuk selanjutnya dikembangkan dalam pemberdayaan mastarakat tani.

\section{HASIL DAN PEMBAHASAN Kondisi Umum}

Kecamatan Mlati merupakan salah satu dari 17 kecamatan yang ada di Kabupaten Sleman, dengan luas wilayah sebesar 28,52 $\mathrm{Km} 2$ atau $2.852 \mathrm{Ha}$, yang terdiri dari 5 desa yaitu Desa Sinduadi, Desa Tlogoadi, Desa Sumberadi, Desa Sendangadi dan Desa Tirtoadi.

Desa Tlogoadi mempunyai 12 dusun, $88 \mathrm{RT}$, dan $35 \mathrm{RW}$, setiap dusun memiliki kelompok tani dengan jumlah total 28 poktan dan terdiri 1 gapoktan. Luas Lahan desa Tlogoadi sebesar 667,10 Ha dengan ketinggian $500 \mathrm{mdpl}$ suhu rata-rata 26-27 Celcius dan $\mathrm{pH}$ tanah berkisar 6-7. Luas tanam di desa Tlogoadi mencapai 267,02 $\mathrm{Ha}$ terdiri dari tanaman pangan, 
hortikultura dan perkebunan dengan dominasi tanaman pangan yaitu tanaman padi.

Jumlah Penduduk di Desa Tlogoadi berjumlah 13.416 jiwa yang terdiri dari laki-laki sebanyak 6.704 jiwa dan perempuan 6.712 jiwa dengan total kepala keluarga sebanyak 4.618 KK. Jumlah penduduk yang bekerja di bidang pertanian sendiri berjumlah 664 orang yang terdiri dari 270 orang petani dan 394 orang buruh tani.

\section{Teknologi Inovasi Budidaya Jahe Merah}

Hasil rekapitulasi benchmarking aspek teknologi inovasi budidaya dengan informan kunci dapat dilihat pada tabel 1. Berdasarkan data Tabel 1, dapat diketahui bahwa kekurangan dari kebun Vista Agro Media yaitu belum melakukan perendaman rimpang jahe sebelum di semai. Salah satu tujuan dilakukan perendaman rimpang jahe merah yaitu agar tidak terserang penyakit jamur. Selain itu perlu pemberian dolomit pada media tanam untuk menyuburkan tanah. Kemudian dalam pemupukan ditambah dengan pemberian pupuk organik, urea, SP36 dan KCL agar dapat membantu pertumbuhan tanaman jahe merah, tetapi di berikan dengan dosis yang cukup.

Berdasarkan hasil benchmarking yang dilakukan pada aspek teknologi inovasi budidaya jahe merah, terdapat kelebihan dan kekurangan di Vista Agro Media dan lokasi pembanding. Persiapan lahan di Vista Agro Media dilakukan pada dua tempat berbeda yaitu pada polybag dan lahan terbuka. Persiapan lahan dimulai dengan memilih bibit jahe merah yang segar dan sudah terpilih dengan syarat bibit sudah berumur tua, sementara persiapan lahan yang di lakukan di Kelompok tani Sidomukti ialah membuat bedengan dengan lebar 1 meter dan tinggi bedengan sekitar 25-30 cm. Bobot dari rimpang jahe merah berkisar antara 0,5-0,7 $\mathrm{kg}$ per rumpun, ukurannya kecil berlapis-lapis, daging rimpang berwarna jingga muda sampai merah, seratnya kasar, aromanya tajam dan rasanya pedas, kandungan minyak atsiri paling tinggi sehingga cocok untuk ramuan obat-obatan (Syukur, 2001).

Penyemaian pada bibit jahe merah yang dilakukan di lokasi pembanding mempunyai kelebihan yaitu bibit direndam selama \pm 30 menit dengan tujuan agar bibit yang ditanam tidak terserang jamur dan adanya pemberian kapur dolomit sebagai penetral $\mathrm{pH}$ tanah. Usia semaian di Vista Agro Media dilakukan selama 1 bulan dan ditutupi dengan plastik untuk menghindari air hujan. Penyemaian yang dilakukan di Kelompok Sidomukti juga tidak jauh berbeda, kurang lebih selama 1 bulan di tanah dengan media yang sama dan di tutupi jerami. Hal ini juga bertujuan agar tidak terkena air hujan secara langsung. Tinggi semaian daun jahe di lahan Kelompok Sidomukti jauh lebih tinggi yaitu sekitar $15 \mathrm{~cm}$ dan muncul daun 3-4 lembar.

Penanaman yang dilakukan di Vista Agro Media dengan memperhatikan waktu musim tanam yaitu di awal musim hujan agar dapat memenuhi ketersediaan air yang ada, begitu pun hal yang sama dilakukan di tempat pembanding Kelompok Tani Sidomukti pada awal musim hujan. Pengolahan tanah dilakukan untuk menjadikan tanah gembur, subur, dan mengandung humus. Kemudian ditaburkan pupuk kandang sebagai pupuk dasar. Pemupukan jahe merah di Vista Agro Media dilakukan 2 kali yaitu saat masa penyemaian dan saat masa tanam berumur 4-5 bulan dengan pupuk organik berupa urine kelinci, akan tetapi perlu adanya tambahan menggunakan pupuk kimiawi dalam masa pertumbuhan tanaman seperti KCL, SP36 dan urea. Menurut Engkos (2019) pemupukan dilakukan dengan dua minggu sekali dengan pupuk organik cair yang sudah dibuat dengan cukup membuat media tanamnya basah setelah itu dengan pemberian pupuk urea, SP36, dan KCL sebesar 278 gram per polybag, pemberian 
$25 \%$ pada umur dua bulan setelah tanam

Tabel 1. Hasil Benchmarking Aspek Teknologi Inovasi Budidaya

\begin{tabular}{|c|c|c|c|}
\hline $\begin{array}{c}\text { Faktor } \\
\text { Keberhasilan }\end{array}$ & Kebun Vista Agro Media & Kelompok Tani Sidomukti & Rencana Tindak Lanjut \\
\hline Persiapan lahan & $\begin{array}{l}\text { Persiapan rimpang jahe merah pada } \\
\text { tahap awal menggunakan media } \\
\text { tanam polybag }\end{array}$ & $\begin{array}{l}\text { Persiapan tahap awal di lahan } \\
\text { yaitu pembuatan bedengan. }\end{array}$ & $\begin{array}{l}\text { KSM dan VAM tetap mempertahankan } \\
\text { tahapannya masing-masing. }\end{array}$ \\
\hline Penyemaian bibit & $\begin{array}{l}\text { Belum melakukan perendaman } \\
\text { bibit dengan fungisida; Belum } \\
\text { melakukan penambahan dolomit } \\
\text { pada media tanam; Penyemaian } \\
\text { selama } 1 \text { bulan ditutupi dengan } \\
\text { plastik uv agar tidak terkena hujan; } \\
\text { Tinggi batang semai bibit } 10 \mathrm{~cm} \text {. }\end{array}$ & $\begin{array}{l}\text { Melakukan perendaman bibit } \\
\text { jahe merah dengan fungisida; } \\
\text { Penambahan dolomit pada media } \\
\text { tanam; Penyemaian selama } 1,5 \\
\text { bulan ditutupi daun atau jerami; } \\
\text { Tinggi batang semai bibit } 15 \mathrm{~cm}\end{array}$ & $\begin{array}{l}\text { Melakukan perendaman bibit sebelum } \\
\text { memasuki tahap penyemaian agar } \\
\text { terhindar dari penyakit jamur. Dan } \\
\text { memberikan kapur dolomit pada media } \\
\text { tanam sebagai penetral pH tanah agar } \\
\text { lebih subur. }\end{array}$ \\
\hline penanaman & $\begin{array}{l}\text { Waktu tanam awal musim hujan; } \\
\text { Ditanam dengan ukuran polybag } \\
40 \times 50 \mathrm{~cm} \text { atau } 50 \times 60 \mathrm{~cm}\end{array}$ & $\begin{array}{l}\text { Waktu tanam musim hujan dan } \\
\text { kemarau; Ditanam di lahan } \\
\text { dengan jarak tanam 50x60cm } \\
\text { dalam barisan dan } 20 \mathrm{~cm} \text { antar } \\
\text { baris }\end{array}$ & $\begin{array}{l}\text { Akan mencoba kedepannya menanam di } \\
\text { luar musim tanam selain itu tetap } \\
\text { mempertahankan tahapannya masing- } \\
\text { masing. }\end{array}$ \\
\hline Pemupukan & $\begin{array}{l}\text { Pupuk Organik dan kompos; Pupuk } \\
\text { urea, SP36, KCL }\end{array}$ & $\begin{array}{l}\text { Pupuk organik dan kompos; } \\
\text { Pupuk urea, SP36, KCL }\end{array}$ & $\begin{array}{l}\text { Tetap mempertahankan tahapannya } \\
\text { masing-masing. }\end{array}$ \\
\hline Perawatan & $\begin{array}{l}\text { Penyiangan Gulma seminggu } \\
\text { sekali; Penyiraman 2x sehari; } \\
\text { Pembumbunan media tanam }\end{array}$ & $\begin{array}{l}\text { Penyiangan Gulma seminggu dua } \\
\text { kali; Penyiraman 2x sehari; } \\
\text { Pembumbunan media tanam }\end{array}$ & $\begin{array}{l}\text { Pemeliharaan atau perawatan dapat } \\
\text { dilakukan lebih dari sekali agar } \\
\text { persaingan gulma dan tanaman tidak } \\
\text { saling merebut unsur hara. }\end{array}$ \\
\hline $\begin{array}{l}\text { Pengendalian } \\
\text { Hama dan } \\
\text { penyakit }\end{array}$ & $\begin{array}{l}\text { Penyemprotan fungisida; Belalang, } \\
\text { kumbang, ulat; Busuk rimpang }\end{array}$ & $\begin{array}{l}\text { Penyemprotan insektisida dan } \\
\text { fungisida; Hama penggulung } \\
\text { daun, ulat; Busuk rimpang }\end{array}$ & $\begin{array}{l}\text { Melakukan penyemprotan dalam } \\
\text { membasmi serangan hama penyakit } \\
\text { dengan fungisida dan insektisida. }\end{array}$ \\
\hline Panen & $\begin{array}{l}\text { Panen usia muda } 8 \text {-10 bulan; Panen } \\
\text { untuk bibit berikutnya usia } 1 \text { tahun; } \\
\text { Proses panen dari polybag. }\end{array}$ & $\begin{array}{l}\text { Panen usia } 8-10 \text { bulan; Panen } \\
\text { untuk bibit berikutnya usia } 1 \\
\text { tahun; Proses panen dari lahan. }\end{array}$ & $\begin{array}{l}\text { Pada saat melakukan pemanenan tetap } \\
\text { mengikuti standar operasional prosedur } \\
\text { sesuai waktu usia panen yang di } \\
\text { harapkan. }\end{array}$ \\
\hline
\end{tabular}

(Sumber: hasil olah data)

Kandungan unsur hara dalam suatu pupuk tidak akan pernah mencapai 100\%. Hal ini disebabkan unsur hara membutuhkan pengikat untuk membentuk kristal atau butiran-butiran. (Rajiman, 2020). Kelompok Tani Sidomukti memberikan pupuk organik, urea, SP36 dan KCL yang menunjang pertumbuhan tanaman jahe merah serta adanya penambahan kapur dolomit yang dapat memperbaiki kesuburan.

Perawatan atau pemeliharaan yang ada di Vista Agro Media sendiri pada jahe merah ialah dengan melakukan penyiraman sebanyak 2 kali dalam sehari yaitu pagi dan sore, serta adanya pembersihan tanaman gulma yang tumbuh di sekitar tanaman sekaligus pembumbunan yang merupakan kegiatan untuk menambah media tanam yang berkurang. Pada Kelompok Tani Sidomukti sendiri melakukan penyiraman sebanyak dua kali dalam sehari pagi dan sore, penyiangan gulma dengan seminggu dua kali dikarenakan tempatnya berada di lahan sehingga harus lebih rajin dalam perlakuannya, serta adanya penambahan media tanam saat usia tanaman sudah memasuki 5 bulan ke atas.

Menurut Litbang Pertanian Lampung (2008) penyakit utama pada jahe adalah busuk rimpang yang disebabkan oleh serangan jamur (fusarium oxysporum) tindakan untuk mencegah masuknya bibit penyakit, seperti penggunaan lahan sehat, penggunaan benih sehat, perlakuan benih 
sehat (antibiotik), melakukan pergiliran tanaman, pembersihan sisa tanaman dan gulma, pembuatan irigasi supaya tidak ada air menggenang dan aliran air tidak melalui petak sehat (sanitasi). Vista Agro Media belum maksimal mengatasi masalah serangan hama dan penyakit sehingga terserang jamur dan berdampak pada busuk rimpang. Sedangkan Kelompok Tani Sidomukti sendiri menangani serangan hama penyakit dengan cara menggunakan insektisida dan fungisida. Hama yang sering menyerang di lahan yaitu hama penggulung daun dan ulat serta terkadang adanya jamur yang timbul juga.

Pemanenan yang dilakukan di Vista Agro Media dan Kelompok Tani Sidomukti dilakukan saat usia sekitar 810 bulan sudah dapat dipanen untuk jahe yang ingin dikonsumsi dan untuk yang ingin dijadikan bibit berusia 1 tahun.

Tabel 2. Potensi dan Peluang Pasar

\begin{tabular}{|c|c|c|c|c|c|c|}
\hline $\begin{array}{c}\text { Faktor } \\
\text { Keberhasilan }\end{array}$ & Kebun Vista Agro Media & Lana Dewana Agro & $\begin{array}{c}\text { Ketera- } \\
\text { ngan }\end{array}$ & potensi & peluang & $\begin{array}{c}\text { Rencana Tindak } \\
\text { Lanjut }\end{array}$ \\
\hline Lokasi & $\begin{array}{l}\text { Lokasi strategis tidak } \\
\text { jauh dari kota } \\
\text { Yogyakarta; akses jalan } \\
\text { mudah; terdapat dalam } \\
\text { google maps; kekurangan } \\
\text { tidak kelihatan dari } \\
\text { pinggir jalan, parkir } \\
\text { cukup luas }\end{array}$ & $\begin{array}{l}\text { Lokasi akses jalan } \\
\text { masih kurang; tidak } \\
\text { terlihat dari jalan raya } \\
\text { besar; parkir tidak luas } \\
\text { namun sudah terdapat } \\
\text { dalam google maps; }\end{array}$ & $\begin{array}{l}\text { Vista } \\
\text { lebih } \\
\text { unggul }\end{array}$ & $\sqrt{ }$ & & $\begin{array}{l}\text { Pembuatan plang papan } \\
\text { nama agar mudah di } \\
\text { temukan }\end{array}$ \\
\hline Produk & $\begin{array}{l}\text { Produk yang dijual } \\
\text { tersedia dalam bibit dan } \\
\text { rimpang serta bibit lain } \\
\text { seperti durian, pisang, } \\
\text { kelapa, lengkeng dan } \\
\text { tanaman hias. }\end{array}$ & $\begin{array}{l}\text { Produk yang dijual } \\
\text { bibit dan beberapa } \\
\text { tanaman obat lainnya } \\
\text { seperti kunyit, } \\
\text { temulawak, porang } \\
\text { dan bawang dayak. }\end{array}$ & sama & $\sqrt{ }$ & $\sqrt{ }$ & $\begin{array}{l}\text { Menambah jenis } \\
\text { tanaman lain agar ketika } \\
\text { konsumen datang dapat } \\
\text { memenuhi sesuai } \\
\text { permintaan. }\end{array}$ \\
\hline Konsumen & $\begin{array}{l}\text { Konsumen berasal di } \\
\text { sekitar dan luar kota } \\
\text { Yogyakarta seperti } \\
\text { Sragen, Sukoharjo, } \\
\text { Karanganyar, kebumen, } \\
\text { solo dan lain-lain. }\end{array}$ & $\begin{array}{l}\text { Konsumen tidak hanya } \\
\text { berasal dari sekitar } \\
\text { saja namun terkadang } \\
\text { datang dari luar kota } \\
\text { Yogyakarta. }\end{array}$ & Sama & & $\sqrt{ }$ & $\begin{array}{l}\text { Memperluas target pasar } \\
\text { melalui produk yang } \\
\text { dijual sesuai kualitas } \\
\text { yang diberikan sehingga } \\
\text { konsumen datang } \\
\text { kembali membeli. }\end{array}$ \\
\hline promosi & $\begin{array}{l}\text { Promosi yang dilakukan } \\
\text { melalui media online dan } \\
\text { offline sehingga } \\
\text { masyarakat luas lebih } \\
\text { mengenal. }\end{array}$ & $\begin{array}{l}\text { Promosi yang } \\
\text { dilakukan yaitu } \\
\text { dengan whatsapp dan } \\
\text { facebook serta juga } \\
\text { dari mulut ke mulut. }\end{array}$ & $\begin{array}{l}\text { Vista } \\
\text { Agro } \\
\text { lebih } \\
\text { unggul }\end{array}$ & & $\sqrt{ }$ & $\begin{array}{l}\text { Meningkatkan promosi } \\
\text { dari berbagai sisi } \\
\text { khususnya dalam media } \\
\text { online ataupun offline. }\end{array}$ \\
\hline Harga & $\begin{array}{l}\text { Harga bibit } 1 \text { polybag } \\
\text { Rp. } 3000 \text { kemudian untuk } \\
\text { rimpang tersedia } 1 \mathrm{~kg} \\
\text { yaitu Rp. } 50.000 \text { grade } \mathrm{A} \text {, } \\
\text { Rp. } 45.000 \text { grade } \mathrm{B} \text {, dan } \\
\text { Rp. } 40.000 \text { grade } \mathrm{C} \text { sesuai } \\
\text { dengan usia dan kualitas. }\end{array}$ & $\begin{array}{l}\text { Harga bibit } 1 \text { polybag } \\
\text { dijual sebesar Rp. } \\
3000 \text { ukuran } \\
10 \mathrm{~cm} \times 15 \mathrm{~cm} \text { dan juga } \\
\text { tersedia dalam bentuk } \\
\text { rimpang } 1 \mathrm{~kg} \text { sebesar } \\
\text { Rp. } 50.000\end{array}$ & Sama & $\sqrt{ }$ & & $\begin{array}{l}\text { Menjaga standardisasi } \\
\text { yang ada dengan selalu } \\
\text { melihat harga di pasaran } \\
\text { supaya tetap dapat } \\
\text { bersaing dan } \\
\text { mempertahankan tanpa } \\
\text { membuat konsumen } \\
\text { berpindah tempat }\end{array}$ \\
\hline Kemitraan & $\begin{array}{l}\text { Menjalin kemitraan } \\
\text { dengan beberapa petani } \\
\text { jahe merah seperti dari } \\
\text { Magelang dan Bantul } \\
\text { sebagai supplier yang } \\
\text { menyediakan bibit jahe } \\
\text { merah. }\end{array}$ & $\begin{array}{l}\text { Menjalin kemitraan } \\
\text { pada petani sekitar } \\
\text { serta membuat plasma } \\
\text { jahe merah pada } 15 \\
\text { orang yang tersebar di } \\
\text { beberapa Kecamatan } \\
\text { yang ada di DIY dan } 1 \\
\text { KWT di desa. }\end{array}$ & $\begin{array}{l}\text { Lana } \\
\text { Dewana } \\
\text { Agro } \\
\text { unggul }\end{array}$ & $\sqrt{ }$ & & $\begin{array}{l}\text { Menjalin mitra dengan } \\
\text { petani sekitar tanpa } \\
\text { merugikan dan menjaga } \\
\text { hubungan yang baik } \\
\text { dengan membangun rasa } \\
\text { percaya satu sama } \\
\text { lainnya. }\end{array}$ \\
\hline $\begin{array}{l}\text { Kerja sama } \\
\text { instansi } \\
\text { terkait }\end{array}$ & $\begin{array}{l}\text { Belum adanya melakukan } \\
\text { kemitraan dengan suatu } \\
\text { instansi terkait. }\end{array}$ & $\begin{array}{l}\text { Belum adanya } \\
\text { melakukan kemitraan } \\
\text { dengan instansi } \\
\text { seperti Dinas Pertanian } \\
\text { Sleman dan Kota } \\
\text { Yogyakarta. }\end{array}$ & sama & & $\sqrt{ }$ & $\begin{array}{l}\text { Mengajukan atau } \\
\text { koordinasi bersama } \\
\text { penyuluh setempat agar } \\
\text { dapat terhubung dengan } \\
\text { instansi terkait. }\end{array}$ \\
\hline
\end{tabular}




\section{Potensi dan Peluang Pasar}

Hasil benchmarking aspek potensi dan peluang pasar usaha jahe merah di Vista Agro Media dengan lokasi pembanding dapat dilihat pada tabel 2 . Berdasarkan hasil benchmarking yang telah di lakukan pada aspek potensi dan peluang pasar budidaya tanaman jahe merah diperoleh kelebihan dan kekurangan yang di miliki di Vista Agro Media ataupun di Lana Dewana Agro.Kelebihan yang dimiliki antara lain ialah letak lokasi dan promosi. Menentukan lokasi yang mudah bisa dijadikan sebagai salah satu strategi atau taktik yang dapat dilakukan oleh perusahaan.

Menurut Anjarwan (2018) lokasi merupakan faktor penting untuk pelanggan datang berkunjung, lokasi yang mudah di capai serta suasana lingkungan yang nyaman akan menarik bagi konsumen datang membeli. Perbandingan antara lokasi Vista Agro Media lebih unggul di mana Vista Agro Media, memiliki lokasi cukup strategis dan tidak jauh dari jarak kota. Sedangkan untuk Lana Dewana Agro letak lokasi tidak begitu strategis dan akses jalan cukup kecil namun kedua tempat sudah bisa dilihat melalui google maps.

Produk dari Vista Agro media menyediakan bibit dan rimpang jahe merah serta beberapa tanaman lain seperti bibit durian, pisang, kelapa, lengkeng, serta tanaman hias. Pada Lana Dewana Agro juga membudidayakan bibit jahe merah dan tanaman lain seperti kunyit, temulawak, porang, bawang dayak.

Konsumen Vista Agro Media tidak hanya melayani masyarakat di sekitar namun konsumen yang datang terkadang berasal dari luar wilayah kota Yogyakarta seperti Sragen, Karanganyar, Solo, Kebumen. Hal ini Sejalan dengan penelitian Hallowel (2002) tentang kepuasaan pelanggaan memiliki potensi untuk membangun loyalitas. Pelanggan yang loyal memiliki kecenderungan lebih rendah untuk berpindah produk atau jasa, kurang sensitif terhadap harga, membeli lebih sering atau lebih banyak, menjadi strong word of mouth dan menciptakan business referrals. Begitu pun Lana Dewana Agro melayani konsumen sekitar namun terkadang dari luar kota Yogyakarta.

Promosi yang dilakukan di Vista Agro Media sudah melalui penggunaan social media dan juga mempunyai website sendiri serta youtube chanel sehingga dapat memperluas pasar. Tjiptono (2002) mengemukakan bahwa promosi adalah bentuk komunikasi pemasaran artinya aktivitas pemasaran yang berupaya menyebarkan informasi, mempengaruhi dan membujuk serta mengingatkan sasaran atau perusahaan dan produknya agar bersedia membeli, menerima produk yang ditawarkan oleh perusahaan yang bersangkutan.

Bibit dijual pada polybag ukuran 10 cm x 15 cm seharga Rp.3000, sedangkan rimpang jahe merah dengan kate-gori per kilo gramnya sebesar Rp.50.000, Rp. 45.000, dan Rp. 40.000, sedangkan di Lana Dewana Agro juga tidak jauh berbeda dengan harga bibit yang dijual sebesar Rp. 3000 dalam per polybag ukuran $10 \mathrm{~cm} \times 15 \mathrm{~cm}$ serta tersedia dalam bentuk rimpang dengan berat $1 \mathrm{~kg} \mathrm{Rp}$. 50.000 .

Menurut Notoatmodjo (2003), kemitraan adalah suatu kerja sama formal antara individu-individu, kelompokkelompok atau organisasi-organisasi untuk mencapai suatu tugas atau tujuan tertentu. Hal ini sebenarnya di lakukan baik di Vista Agro Media maupun di Lana Dewana Agro kerja sama kedua usaha belum terlalu luas oleh karena itu perlu adanya rencana pengembangan dengan mengajak petani untuk menanam jahe merah. Kerja sama dengan instansi terkait baik Vista Agro Media dan Lana Dewana Agro belum menjalin kemitraan dengan instansi terkait, seharusnya jika ada dukungan dari dinas atau pemerintah 
setempat dapat memungkinkan usaha tersebut lebih maju dan berkembang.

\section{Rencana Pengembangan usaha dengan Bussines Model Canvas (BMC)}

Rencana pengembangan usaha tanaman jahe merah di Vista Agro Media diperoleh melalui hasil rancangan Bussines Model Canvas (BMC) yang dapat dilihat pada Gambar 1.

Menurut Zulkarnain et al. (2020) BMC dibagi menjadi sembilan model utama yang terdiri sebagai berikut: 1) Customer Segment menggambarkan sekelompok orang atau organisasi yang menjadi target yang dijangkau atau yang dilayani, 2) Value Proposition merupakan daya tarik bagi pembeli yang ditawarkan oleh perusahaan sehingga memenuhi kepuasan konsumen, 3) Channels adalah cara perusahaan untuk menjangkau konsumen, 4) Customer Relationship yaitu suatu cara yang dilakukan perusahaan untuk membangun suatu hubungan dengan konsumen, 5) Revenue Stream merupakan sumber pemasukan bagi perusahaan yang didapatkan dari daya tarik yang diciptakan perusahaan untuk konsumen, 6) Key Resource adalah sumber daya utama yang dimiliki perusahaan dalam membangun bisnisnya, 7) Key Activities yaitu aktivitas utama yang terkait dengan produksi di perusahaan, 8) Key Partnership yaitu mitra kerja yang dilakukan oleh perusahaan, 9) Cost Structure yaitu biaya-biaya yang dikeluarkan oleh perusahaan untuk mendukung semua aktivitas - aktivitas di atas.

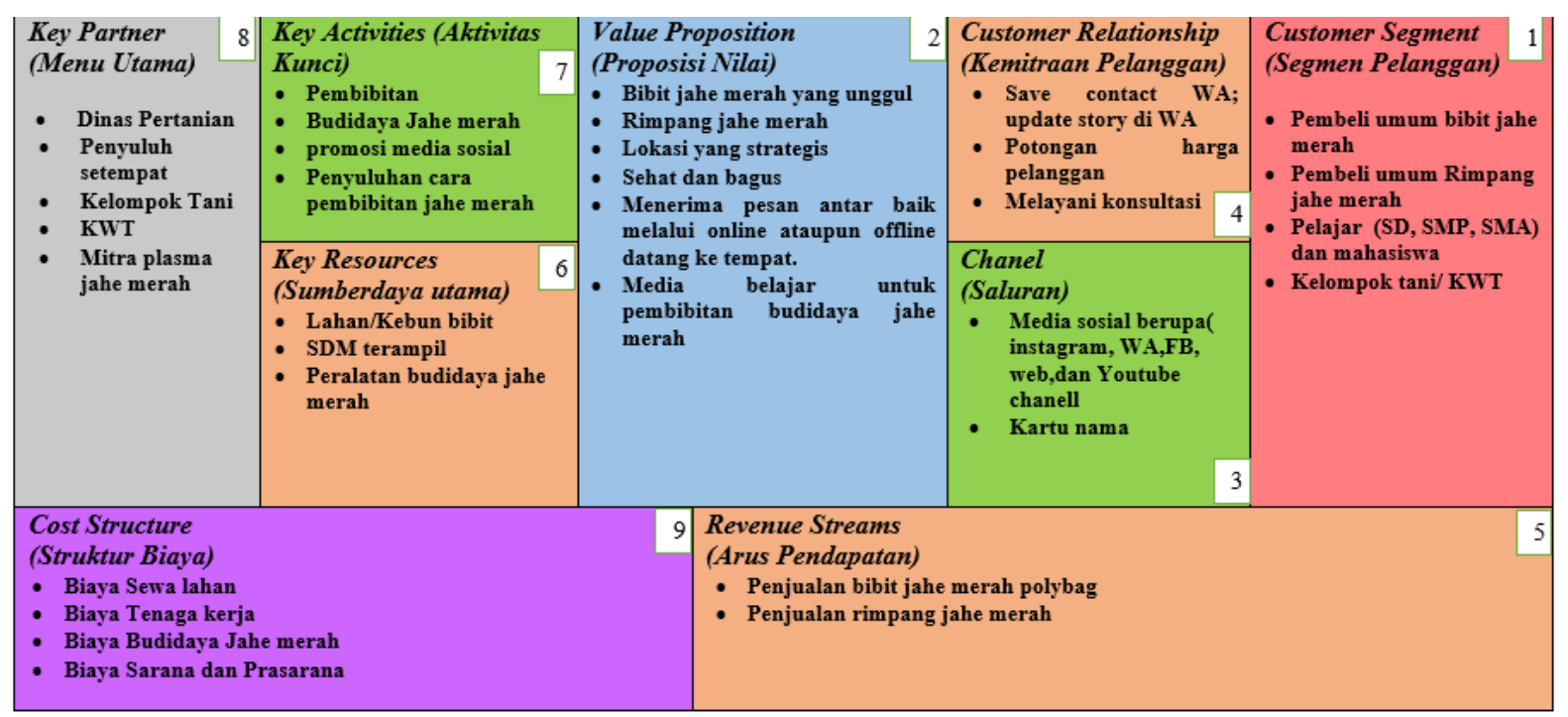

Gambar 1. Business Model Canvas Pengembangan Vista Agro Media

Berdasarkan dari hasil aktivitas utama (key activities) yang didapatkan di BMC dalam mendukung pengembangan usaha tanaman jahe merah di kebun Vista Agro Media berupa kegiatan pembibitan dari budidaya jahe merah, terus melakukan promosi dengan media sosial dan adanya penyuluhan materi guna bertujuan memajukan usaha tersebut maka dibuatlah Rencana Pemberdayaan berupa kegiatan penyuluhan teknik inovasi pada pembibitan jahe merah di
Vista Agro Media terhadap masyarakat tani sekitar dengan mengajak mereka yang mau membudidayakan jahe merah sehingga terciptanya kerja sama atau mitra utama tetap (key partner). Tujuan tersebut agar pemenuhan dalam kebutuhan produksi jahe merah dapat terpenuhi dan petani yang terlibat bekerja sama mendapatkan hubungan timbal balik atau sama-sama diuntungkan melalui usaha budidaya jahe merah tersebut. 


\section{Rencana Tindak Lanjut}

Rencana pengembangan yang akan ditindak lanjuti untuk kemajuan pengembangan usaha budidaya tanaman jahe merah di Vista Agro Media yaitu dapat melakukan peningkatan produksi jahe merah melalui adanya kerja sama dengan mengajak petani atau KWT sekitar desa Tlogoadi menjadi bagian Vista yang melakukan kegiatan budidaya jahe merah baik di lahan atau pun di polybag dengan memanfaatkan sekitar pekarangan rumah. Kegiatan yang pertama dilakukan ialah dengan memberi penyuluhan terhadap anggota petani atau KWT yaitu bagaimana cara pembibitan jahe merah yang baik dan benar sampai tahap panen. Ketika sudah siap panen dapat menawarkan kepada Vista Agro Media sehingga ke depan diharapkan dapat menjadi partner dalam usaha yang dijalankan sekaligus mendukung pengembangan usaha tanaman jahe merah.

\section{SIMPULAN DAN SARAN}

Berdasarkan hasil kajian maka dapat disimpulkan bahwa penerapan teknologi inovasi di Vista Agro Media yang sudah optimal dalam budidaya jahe merah ialah pemberian plastik $u v$ atau paranet serta pemberian pupuk organik berupa urine kelinci dan kompos. Sedangkan yang belum optimal terjadi pada tahap pembibitan yaitu belum melakukan penggunaan kapur dolomit dan fungisida. Agar menjadi optimal dilakukan dengan perendaman dan penyemprotan sehingga bibit jahe merah yang dihasilkan menjadi berkualitas.

Potensi dan peluang pasar pada Vista Agro Media ialah lokasi yang strategis, produk yang ditawarkan selalu tersedia, harga yang murah. Sedangkan peluang yang ada ialah kegiatan promosi baik secara online ataupun offline serta berpeluang untuk mengi-kuti pameran dari dinas atau instansi terkait.

Model Pemberdayaan dilaksanakan guna mendukung peningkatan produksi jahe merah ialah menjalin kerja sama/kemitraan dengan masyarakat tani/Poktan dengan melaksanakan penyuluhan /pemberdayaan agar mereka membudidayakan jahe merah sehingga saat panen hasilnya dapat dipasarkan pada Vista Agro Media dan kedua belah pihak dapat saling diuntungkan. Kegiatan penyuluhan/pemberdayaan dilakukan dengan materi cara pembibitan Jahe merah pada media polybag kepada anggota KWT Umbulasri

Hasil penyuluhan tersebut menunjukkan adanya peningkatan aspek pengetahuan sebesar 96\%, lalu aspek sikap sebesar 98,66\% dan aspek keterampilan diukur dengan pengamatan praktik secara langsung dan di dukung post-test yaitu $98,66 \%$.

\section{PUSTAKA ACUAN}

Anjarwan, S. (2018). Pengaruh Kelengkapan Produk, Persepsi Harga, dan Lokasi Terhadap Kepuasan Pelanggan Pada Toserba DM BARU 1 Pleret Bantul Yogyakarta. Jurnal Ekobis Dewantara, 1 (3).

Balai Penelitian Tanaman Rempah dan Obat (BALITTRO). (2013). Standar Prosedur Operasional Budidaya Jahe. Balai Penelitian Tanaman Obat dan Aromatik, Bogor.

Balai Besar Pengkajian dan Pengembangan Teknologi Pertanian Lampung. (2008). Teknologi Budidaya jahe. Balai Penelitian dan Pengembangan Pertanian.

BPS Kabupaten Sleman. (2020). Kabupaten Sleman dalam Angka 2020. Badan Pusat Statistik. Yogyakarta.

Direktorat Jenderal Hortikultura. (2020). Potensi Permasalahan dan Tantangan Pembangunan Hortikultura. Jakarta.

Direktorat Jenderal Perkebunan. (2006). 
Daftar Komoditi Binaan. Keputusan Menteri Pertanian Nomor 511/KPTS/PD.310/9/2006 tentang Jenis Komoditi.

Engkos, K., dan Irwan. (2019). Budidaya Jahe Merah Hasilkan Hingga Tiga Kali Lipat-Cet.1. Jakarta: Penebar Swadaya Hallowell, Roger. (2002). The Relationship of Customer Satisfaction and Loyalty, Sinar Baru Algesindo, Bandung

Julia, B. (2005). Memadu Metode Penelitian Kualitatif \& Kuantitatif (Terjemahan: Nuktaf Arfawie Kurde) Pustaka Pelajar, Yogyakarta.

Notoatmodjo, Soekidjo. (2003). Pengembangan Sumber Daya Manusia, Jakarta: PT. Rineka Cipta.

Programa Kecamatan Mlati. (2019).
Daerah Istimewa Yogyakarta.

Profil Desa Tlogoadi Tahun 2019. (2019). Daerah Istimewa Yogyakarta.

Rajiman. (2020). Pengantar pemupukan. In Deepublish.

Sugiyono (2015). Metode Penelitian Kombinasi (Mix Methods). Bandung: Alfabeta.

Syukur, C. (2001). Agar Jahe Berproduksi Tinggi. Penebar Swadaya, Jakarta.

Tjiptono, F. (2002). Strategi Pemasaran. Yogyakarta. Penerbit Andi.

Zulkarnain., Saputra, M. G., \& Silvia, D. (2020). Strategi Pengembangan Bisnis Melalui Pendekatan Business Model Canvas Pada PT Pitu Kreatif Berkah. Journal Industrial Services, 6(1), 5561. 